\title{
JURNALISTIK ISLAMI DI MEDIA MASSA
}

\author{
Oleh:Qudratullah \\ Jurnalis Tribun Timur Makassar \\ E-mail:qudratullahrustam@gmail.com
}

\begin{abstract}
Abstrak
Media massa saat ini menjadi alat komunikasi yang banyak digunakan untuk berkomunikasi. Hal tersebut dikarenakan perkembangan teknologi informasi dan komunikasi yang diikuti dengan perkembangan media massa. Media massa telah menjadi industri besar di tengah kehidupan masyarakat. Jangkauan pengiriman pesan dari komunikator kepada komunikan juga sangat luas sehingga penyebaran informasi juga semakin mudah dan cepat. Media saat ini sering kali digunakan sebagai alat untuk menyampaikan dakwah dari da'i kepada mad'u. Dalam dunia jurnalistik, para jurnalis dianggap tidak hanya sekedar sebagai penyampai informasi tetapi juga dianggap sebagai penyeru kebajikan. Jurnalis yang idealnya melakukan kegiatan jurnalistik dapat dikatakan layaknya seorang $d a$ ' $i$ yang diistilahkan sebagai jurnalistik dakwah. Jurnalistik dakwah merupakan sebagai suatu proses meliput, mengolah, dan menyebarluaskan berbagai peristiwa dengan muatan nilai-nilai kebenaran yang sesuai dengan ajaran Islam, khususnya yang menyangkut agama dan umat Islam. Jurnalistik dakwah sering kali diidentikkan dengan dakwah melalui tulisan atau biasa disebut dakwah kitabah. Dakwah kitabah yaitu proses penyampaian ajaran Islam melalui bahasa tulisan bisa berupa buku, majalah, jurnal, surat kabar, pamflet, dan brosur yang berisikan pesan-pesan keislaman. Dakwah tersebutlah yang dilakukan oleh para jurnalis yang menyebarluaskan pesan dakwah melalui informasi aktual dan kebenaran melalui tulisannya di media massa.
\end{abstract}

Kata Kunci: Jurnalistik Islami, dakwah, media massa. 


\begin{abstract}
Mass media is now a communication tool that is widely used to communicate. It takes place because the development of information and communication technology is growing up with the development of mass media. The mass media has become a major industry in people's lives. The reach of message from communicator to the communicant is also very broad, so that the dissemination of information is also getting easier and faster. The media today is often used as a tool to convey $d a^{\prime} i$ from $d a^{\prime} i$ to mad'u. In the world of journalism, journalists cannot only be a conveyor of information as well as an advocate of virtue. Journalists who ideally do journalistic activities can be said as a $d a^{\prime} i$ who is so-called as a journalism $d a^{\prime} w a h$. Journalism $d a^{\prime} w a h$ is a process of covering, processing, and disseminating various events with content values that are in accordance with Islamic teachings, especially those concerning religion and Muslims. Journalism da'wah often identifies with da'wah through writing or commonly called da'wah kitabah. Da'wah Kitabah is the process of delivering Islamic teachings through written language can be books, magazines, journals, newspapers, pamphlets, and brochures containing Islamic messages. The $d a^{\prime} w a h$ is done by the journalists who disseminate the message of $d a^{\prime}$ wah through the actual and secret information through writing in the mass media.
\end{abstract}

Key words: Islamic journalism, dakwah, mass media 


\section{PENDAHULUAN}

\section{Latar Belakang}

Dewasa ini perkembangan tehnologi komunikasi massa mengalami perkembangan yang sangat pesat. Hal ini dibuktikan mudahnya berhubungan dengan orang yang berada di negara lain. Jarak yang dulunya terasa amat jauh, kini sudah terasa amat dekat dengan hadirnya alat telekomunikasi. Berbagai informasi dan peristiwa yang terjadi di belahan dunia lain dengan mudah dan cepat diketahui.

Selain informasi dan peristiwa yang cepat, juga masyarakat dengan mudahnya mendapatkan pilihan informasi. Sekarang ini, banyak pilihan informasi yang didapatkan seperti informasi dari media massa seperti surat kabar dan majalah, juga dari media elektronik seperti radio dan telervisi, serta media online yang memberikan informasi yang beragam dan mendunia secara cepat dan praktis.

Untuk mendapatkan informasi atau berita, maka ini adalah tugas seorang wartawan (jurnalis).Kegiatan jurnalistik, telah dicontohkan zaman dahulu seperti pembukuan Al-qur'an yang kita kenal dengan mushaf dalam perspektif jurnalistik, Al-qur'an adalah karya jurnalistik juga, yakni diformat dalam buku yang isinya firman-firman Allah swt.demikian pula, termasuk karya jurnalistik adalah kitab-kitab kumpulan hadis seperti Shahih Bukhari dan Shahih Muslim, dan sebagainya.

Semua kegiatan ini adalah profesi seorang wartawan (jurnalis). Profesi sebagai wartawan (jurnalis) dalam masyarakat sangatlah penting, sama pentingnya dengan peran yang dimainkan oleh para ilmuwan, cendikiawan dan para ulama. Seorang wartawan harus memberikan informasi yang akurat, lengkap, jelas, jujur serta aktual, dan juga dapat memberikan prediksi serta petunjuk ke arah perubahan dan transformasi. Selain itu wartawan pula harus mempertanggungjawabkan berita yang didapatkannya. 
Meskipun pekerja jurnalistik memiliki kebebasan, namun tidak dapat terlepas dari tanggungjawab.Tak sedikit wartawan yang menyalahi aturan yang melekat dalam peraturang yang diatur dalam Undang-Undang serta kaidah-kaidah Islam.

Oleh karena itu yang dibutuhkan seorang wartawan adalah kejujuran.Kejujuran dalam mengumpulkan data, mengola dan menyajikan berita, sehingga wartawan harus memahami tentang etika dalam

jurnalistik.Seorang wartawan yang melebih-lebihkan sebuah berita dengan maksud untuk membuat berita itu lebih heboh dan sensasional merupakan pelanggaran etis.Wartawan yang dengan mudah tergoda untuk memperuncing fakta-fakta dengan menghilangkan sebahagian berita, menfokuskan suatu detail yang kecil tetapi menyentil, atau dengan memancing kutipan-kutipan yang provokatif, yang tujuannya bukanlah untuk mengatakan suatu kebenaran melainkan untuk menarik perhatian. ${ }^{1}$ Tidak hanya itu, masih banyak lagi etika yang perlu diketahui dan dijalankan oleh para jurnalis Islami agar sesuai dengan ajaran Islam.

\section{Rumusan Masalah}

Dari latar belakang yang dibahas sebelumnya, masalah pokok dalam jurnal ini adalah baagaiaman jurnalistik Islami dalam media massa? Dari masalah tersebut, lahir sub masalah sebagai berikut: pertama, bagaimana definisi Jurnalis Islami? Dan bagaimana landasan etika Jurnalis Islami? 


\section{PEMBAHASAN}

Jurnalis Islami

\section{Pengertian Jurnalis Islami}

Jurnaslistik berasal dari bahasa Yunani yakni Journal atau Journe yang berarti catatan harian. ${ }^{2}$ Jurnalistik Islami awalnya identik dengan Dakwah Bil Qalam yaitu dakwah dengan tulisan, seperti lewat tulisan di media massa cetak dan buku, mengingat "pengertian konvensional jurnalistik" yang identik dengan media cetak seperti suratkabar, tabloid, majalah, atau buletin.

Namun, seiring perkembangan media, jurnalistik islami tidak lagi terbatas di media cetak, tapi juga media elektronik (Radio/Televisi) dan media siber (cybermedia, media online, media internet). Feature radio atau feature televisi, misalnya, jika mengandung kebaikan, kebenaran, dan bernilai syi'ar Islam, maka itu termasuk produk jurnalistik dakwah.

Jurnalistik Islami sebagai suatu proses meliput, mengolah, dan menyebarluaskan berbagai peristiwa dengan muatan nilai-nilai kebenaran yang sesuai dengan ajaran Islam, khususnya yang menyangkut agama dan umat Islam. Jurnalistik islami dapat juga dimaknai sebagai proses pemberitaan atau pelaporan tentang berbagai hal yang sarat dengan muatan dan sosialisasi nilai- nilai Islam. ${ }^{3}$

Dapat disimpulkan, jurnalistik islami yaitu proses peliputan dan pelaporan peristiwa yang mengandung pesan dakwah berupa ajakan ke jalan Allah swt. Setiap berita, artikel opini, ataupun feature yang mengandung seruan secara langsung dan tidak langsung, tersurat ataupun tersurat, untuk beriman, berbuat baik (beramal saleh), dan bertakwa kepada Allah swt masuk dalam kategori jurnalistik Islami.

Dalam literatur jurnalistik, Islami masuk dalam jenis Crusade Journalism, yaitu jurnalistik yang memperjuangkan nilai-nilai tertentu, yakni nilai-nilai Islam.Jurnalistik Islami mengemban misi 'amar ma'ruf nahi munkar seperti yang tertuang dalam QS Ali Imran; 104.Jurnalistik islami juga masuk kategori 
Jurnalisme Profetik (Jurnalisme Nabawi), yaitu jurnalistik yang mengemban misi (risalah) kenabian yakni menegakkan tauhid dan syiar Islam. ${ }^{4}$

\section{Dasar Jurnalis Islami}

Dasar hukum Jurnalistik islami yaitu QS Ali-Imran/104 yang juga menjadi dasar aktivitas dakwah secara umum:

$$
\begin{aligned}
& \text { II }
\end{aligned}
$$

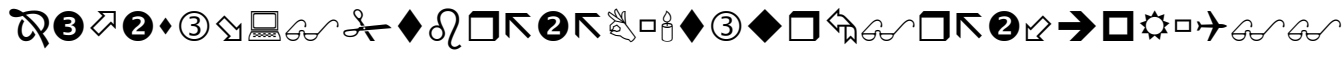

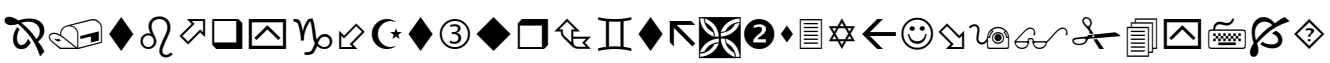

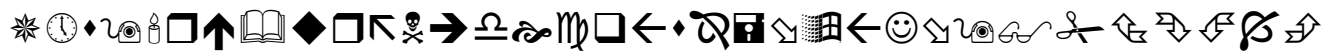

Terjemahnya:

"Dan hendaklah ada di antara kamu segolongan umat yang menyeru kepada kebaikan, menyuruh kepada yang ma'ruf, dan mencegah dari yang munkar. Merekalah orang-orang yang beruntung" 5

Kata minkum pada ayat du atas, ada ulama yang memahaminya dalam arti sebagian, dengan demikian perintah berakwah yang dipesankan oleh ayat ini tidak tertuju pada semua orang. Bagi yang memahaminya demikian, ayat ini buat mereka mengandung dua macam perintah, yang pertama kepada selutuh umat Islam agar membentuk dan menyiapkan satu kelompok khusus yang bertugas melaksanakan dakwah, sedang perintah yang kedua adalah kepada kelompok khusus itu untuk melaksanakan dakwah kepada kebajikan dan ma'ruf serta mencegah kemungkaran. ${ }^{6}$

Ada juga ulama yang memfungsikan kata minkum dalam arti penjelasan sehingga ayat ini merupakan perintah kepada setiap umat muslim untuk melaksanakan tugas dakwah, masing-masing sesuai kemampuannya. Memang, jika dakwah yang dimaksud adalah dakwah yang sempurna, tentu saja tidak semua orang dapat melakukannya. Di sisi lain, kebutuhan masyarakat dewasa ini menyangkut informasi yang benar di tengah arus informasi, bahkan perang 
informasi yang demikian pesat dengan sajian nilai-nilai baru yang sering membingungkan, semua itu menuntut adanya kelompok khusus yang menangani dakwah dan membendung informasi yang menyesatkan. ${ }^{7}$

Menyeru kepada kebaikan (al-khair) dan 'amar ma'ruf nahyi munkar, berdasarkan ayat tersebut, menjadi visi-misi jurnalistik dakwah.Informasi, pesan, tulisan, atau berita yang disebarkan dalam konteks jurnalistik dakwah senantiasa mengacu pada kebaikan dalam perspektif Islam dan bertujuan menegakkan kebenaran serta mencegah hal-hal munkar (bertentangan dengan syariat Islam).

Ciri khas jurnalistik Islami adalah menyebarluaskan informasi tentang perintah dan larangan Allah swt (memberikan message) dan berusaha keras untuk mempengaruhi khalayak, agar sesuai dengan ajaran Islam. Jurnalistik Islami tentu saja menghindari gambar-gambar ataupun ungkapanungkapan pornografis, menjauhkan promosi kemaksiatan, atau hal-hal yang bertentangan dengan syariat Islam, seperti fitnah, pemutarbalikkan fakta, berita bohong, mendukung kemunkaran, dan sebagainya.Jurnalistik Islami harus mampu mempengaruhi khalayak agar menjauhi kemaksiatan, perilaku destruktif, dan menawarkan solusi Islami atas setiap masalah. ${ }^{8}$

Karena juru dakwah menebarkan kebenaran Ilahi, maka jurnalis Islami laksana "penyambung lidah" para nabi dan ulama. Karena itu, ia pun dituntut memiliki sifat-sifat kenabian, seperti Shidiq, Amanah, Tabligh, dan Fathonah.

a. Shidiq artinya benar, yakni menginformasikan yang benar saja dan membela serta menegakkan kebenaran itu. Standar kebenarannya tentu saja kesesuaian dengan ajaran Islam (Al-qur'an dan as-Sunnah). Amanah artinya terpercaya, dapat dipercaya, karenanya tidak boleh berdusta, memanipulasi atau mendistorsi fakta, dan sebagainya.

b. Tabligh artinya menyampaikan, yakni menginformasikan kebenaran, tidak menyembunyikannya. Sedangkan fathonah artinya cerdas dan 
berwawasan luas. Jurnalis Muslim dituntut mampu menganalisis dan membaca situasi, termasuk membaca apa yang diperlukan umat.

c. Jurnalis Islami bukan saja para wartawan yang bergama Islam dengan ajaran agamanya, melainkan juga para cendekiawan Muslim, ulama, mubalig, dan umat Islam pada umumnya yang cakap menulis di media massa. ${ }^{9}$

\section{Landasan Etika Jurnalis Islami}

\section{Kode Etik Jurnalistik Indonesia}

Kemerdekaan berpendapat, berekspresi dan pers adalah hak asasi manusia yang dilindungi Pancasaila, Undang-Undang Dasar 1945, dan Deklarasi Universal Hak Asasi Manusia PBB.Kemerdakaan pers adalah sarana masyarakat untuk memperoleh informasi dan berkomunikasi, guna memenuhi kebutuhan hakiki dan meningkatkan kualitas kehidupan manusia. ${ }^{10}$

Dalam mewujudkan kemerdekaan pers itu, wartawan Indonesia juga menyadari adanya kepentingan bangsa, tanggungjawab sosial, keberagaman masyarakat, dan norma-norma agama. Untuk menjamin kemerdekaan pers dan memenuhi hak public untuk memperoleh informasi yang benar sesuai dengan Kode Etik Jurnalistik: ${ }^{11}$

\section{Pasal 1}

Wartawan Indonesia bersikap independen, menghasilkan berita yang akurat, berimbang, dan tidak beritikad buruk.

Pasal 2

Wartawan Indonesia menempuh cara-cara yang profesional dalam melaksanakan tugas jurnalistik.

\section{Pasal 3}


Wartawan Indonesia selalu menguji informasi, memberitakan secara berimbang, tidak mencampurkan fakta dan opini yang menghakimi, serta menerapkan asas praduga tak bersalah.

\section{Pasal 4}

Wartawan Indonesia tidak membuat berita bohong, fitnah, sadis, dan cabul.

\section{Pasal 5}

Wartawan Indonesia tidak menyebutkan dan menyiarkan identitas korban kejahatan susila dan tidak menyebutkan identitas anak yang menjadi pelaku kejahatan.

Pasal 6

Wartawan Indonesia tidak menyalahgunakan profesi dan tidak menerima suap.

\section{Pasal 7}

Wartawan Indonesia memiliki hak tolak untuk melindungi narasumber yang tidak bersedia diketahui identitas maupun keberadaannya, menghargai ketentuan embargo, informasi latar belakang, dan off the record sesuai dengan kesepakatan.

\section{Pasal 8}

Wartawan Indonesia tidak menulis atau menyiarkan berita berdasarkan prasangka atau diskriminasi terhadap seseorang atas dasar perbedaan suku, ras, warna kulit, agama, jenis kelamin, dan bahasa serta tidak merendahkan martabat orang lemah, miskin, sakit, cacat jiwa atau cacat jasmani.

\section{Pasal 9}

Wartawan Indonesia menghormati hak narasumber tentang kehidupan pribadinya, kecuali untuk kepentingan publik.

Pasal 10

Wartawan Indonesia segera mencabut, meralat, dan memperbaiki berita yang keliru dan tidak akurat disertai dengan permintaan maaf kepada pembaca, pendengar, dan atau pemirsa. 
Pasal 11

Wartawan Indonesia melayani hak jawab dan hak koreksi secara proporsional.

Dalam konteks profesi wartawan, maka sebuah tanggungjawab harus didasarkan atas:

a. Kejujuran

b. Mengabdi untuk kepentingan public

c. Menyampaikan kepada masyarakat apa yang mereka harapkan, serta mengjindari sesuatu yang tidak perlu

d. Melakukan tugas kewartawanan tanpa mengurangi kepercayaan masyarakat terhadap profesi jurnalistik

e. Rasa sensitif terhadap tiap-tiap individu yang akan menjadi sumber berita maupun yang akan kena sasaran berita

f. Melakasanakan fungsi sosial control

g. Hak untuk mrmberitakan, menolak, menjawab untuk menjaga keselamatan sumber berita. $^{12}$

\section{Landasan Jurnalis Islami}

Dalam ranah praktis, jurnalis juga dituntut memiliki kemampuan teknis dan etis sebagaimana dituntunkan dalam Al-qur'an. Hal ini menurut Romli (2003) tercermin dalam berbagai bentuk ahlakul karimah, antara lain:

1. Menyampaikan informasi dengan benar, juga tidak merekayasa atau memanipulasi fakta (QS. Al-Hajj/ 30):

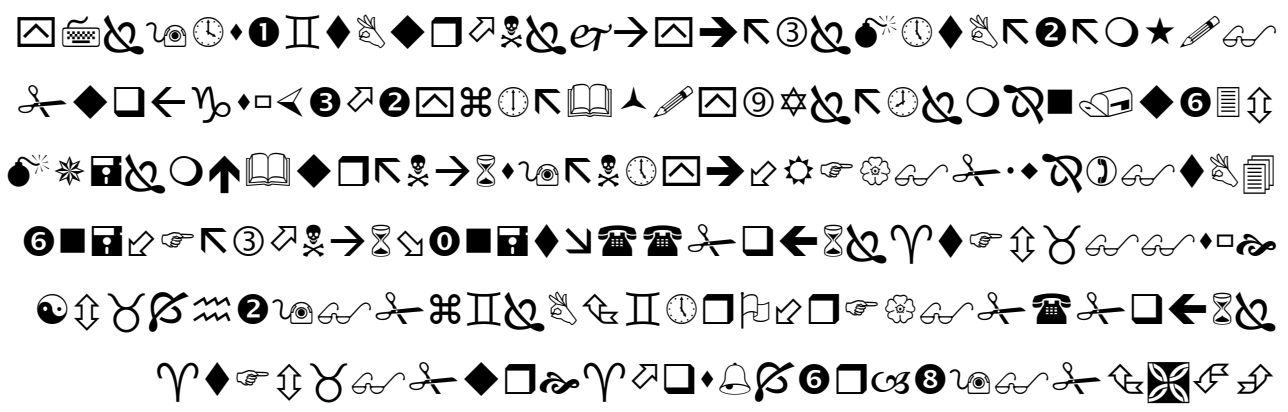


Terjemahnya:

"Demikianlah (perintah Allah).dan barangsiapa mengagungkan apa-apa yang terhormat di sisi Allah. Maka itu adalah lebih baik baginya di sisi Tuhannya.dan Telah dihalalkan bagi kamu semua binatang ternak, terkecuali yang diterangkan kepadamu keharamannya, Maka jauhilah olehmu berhala-berhala yang najis itu dan jauhilah perkataan-perkataan dusta" 13

2. Bijaksana penuh nasihat yang baik, serta argumentasi yang jelas dan baik pula. Karakter, pola pikir, kadar pemahaman objek pembaca harus dipahami sehingga berita yang disusun akan mudah dibaca dan dicerna (QS. An-Nahl: 125):

$$
\begin{aligned}
& \text { オKロ (10) \& }
\end{aligned}
$$

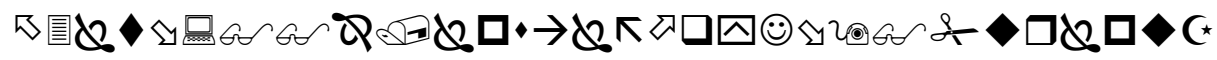

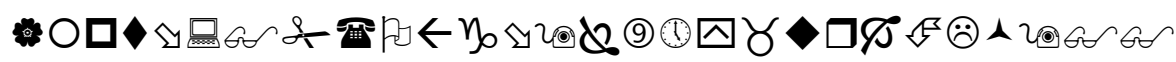

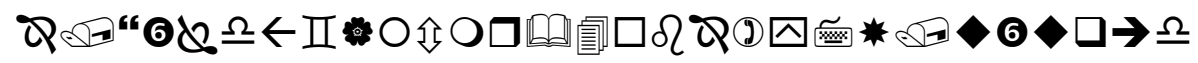

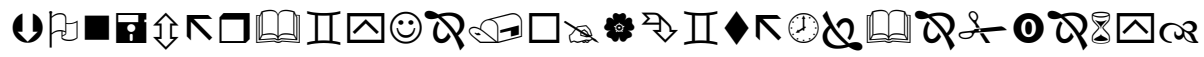

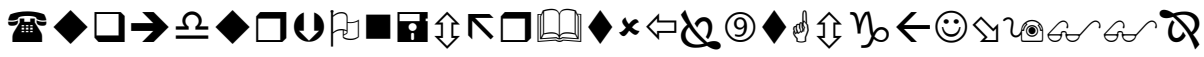

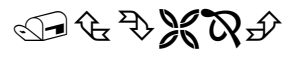

Terjemahannya:

"Serulah (manusia) kepada jalan Tuhan-mu dengan hikmah dan pelajaran yang baik dan bantahlah mereka dengan cara yang baik. Sesungguhnya Tuhanmu dialah yang lebih mengetahui tentang siapa yang tersesat dari jalan-Nya dan dialah yang lebih mengetahui orang-orang yang mendapat petunjuk"14

Hikmah: ialah perkataan yang tegas dan benar yang dapat membedakan antara yang hak dengan yang bathil. 
3. Meneliti fakta atau cek-ricek. Untuk mencapai ketepatan data dan fakta sebagai bahan baku berita yang akan ditulis, jurnalis muslim hendaknya mengecek dan meneliti kebenaran fakta di lapangan dengan informasi awal yang ia peroleh agar tidak terjadi ghibah dan fitnah.(QS. alHujurat/6):

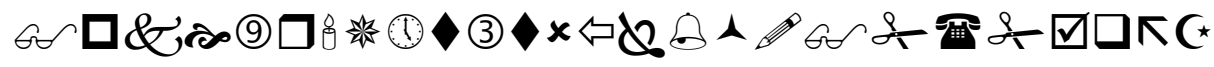
• है\&

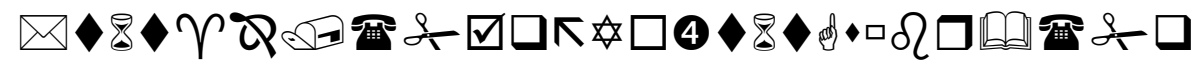

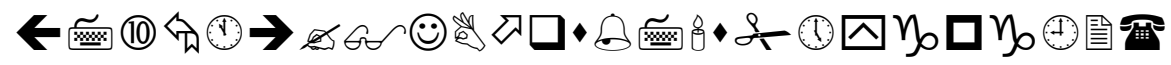

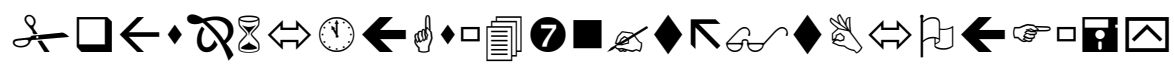

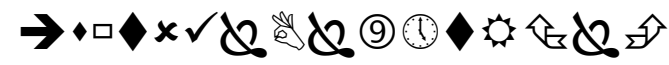

Terjemahnya:

"Hai orang-orang yang beriman, jika datang kepadamu orang fasik membawa suatu berita, Maka periksalah dengan teliti agar kamu tidak menimpakan suatu musibah kepada suatu kaum tanpa mengetahui keadaannya yang menyebabkan kamu menyesal atas perbuatanmu itu"15

4. Tidak mengolok-olok, mencaci-maki, atau melakukan tindakan penghinaan sehingga menumbuhkan kebencian (QS. Al-Hujarat: 11);

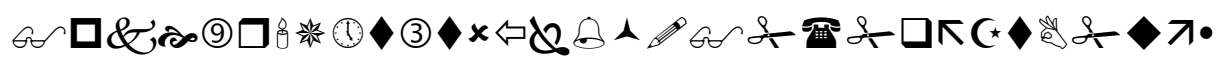

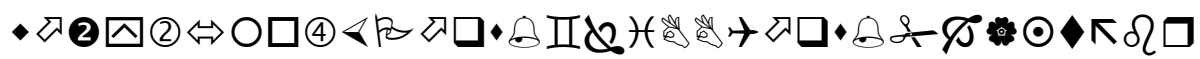

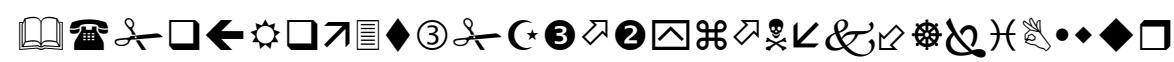

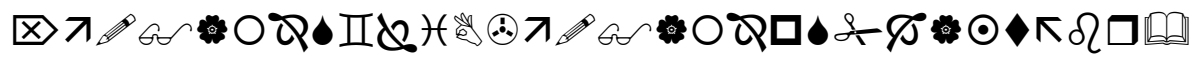

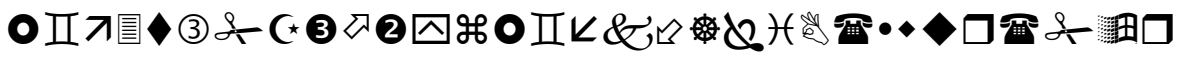

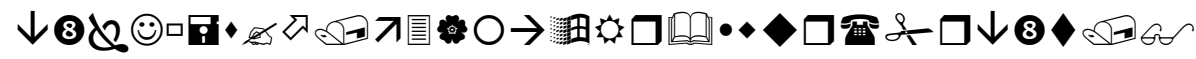

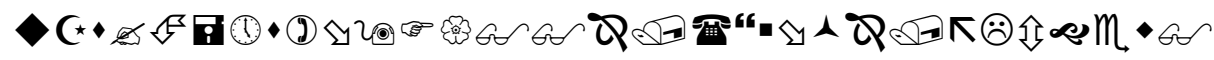




\section{क्ष 国 II

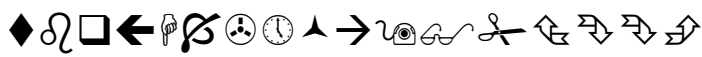

Terjemahnya:

"Hai orang-orang yang beriman, janganlah suatu kelompok mengolok-olok kaum yang lain, boleh jadi yang ditertawakan itu lebih baik dari mereka. dan jangan pula sekumpulan perempuan merendahkan kumpulan lainnya, boleh jadi yang direndahkan itu lebih baik. dan janganlah suka mencela dirimu sendiri dan jangan memanggil dengan gelaran yang mengandung ejekan. seburuk-buruk panggilan adalah (panggilan) yang buruk sesudah iman dan barangsiapa yang tidak bertobat, Maka mereka Itulah orang-orang yang zalim." 16

Jangan mencela dirimu sendiri maksudnya ialah mencela antara sesama mukmin karena orang-orang mukmin seperti satu tubuh. Panggilan yang buruk ialah gelar yang tidak disukai oleh orang yang digelari, seperti panggilan kepada orang yang sudah beriman, dengan panggilan seperti: Hai fasik, Hai kafir dan sebagainya.

5. Menghindari prasangkaatau su'udzon. Dalam pengertian hukum, jurnalis hendaknya memegang teguh "asas prduga tak bersalah" seperti yang tertulis pada QS Al-hujurat/12:

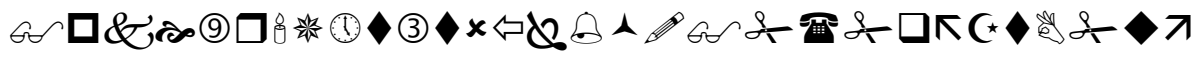
要 \& II $\lambda \rightarrow$ 206 \&

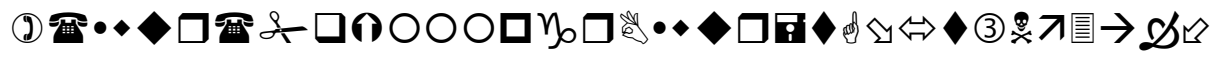
$\rightarrow$ * G G

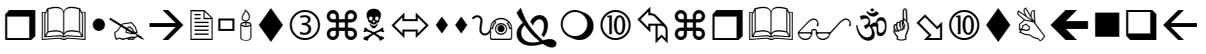




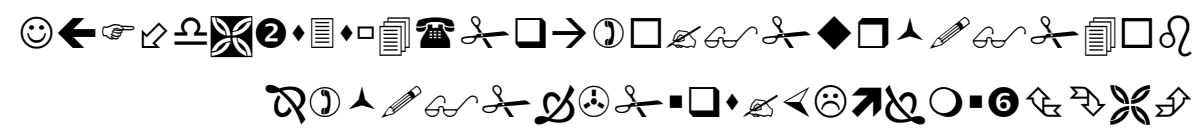

Terjemahnya:

"Hai orang-orang yang beriman, jauhilah kebanyakan prasangka (kecurigaan), Karena sebagian dari purba-sangka itu dosa.dan janganlah mencari-cari keburukan orang dan janganlah menggunjingkan satu sama lain. Adakah seorang diantara kamu yang suka memakan daging saudaranya yang sudah mati?Maka tentulah kamu merasa jijik kepadanya.dan bertakwalah kepada Allah. Sesungguhnya Allah Maha Penerima Taubat lagi Maha Penyayang"17

Kemudian, dari Abu Khurairah ra berkata:

"Rasulullah saw bersabda, jauhilah oleh kalian segala dugaan karena dugaan itu adalah perkataan yang paling dusta. Dan janganlah kalian saling mencari-cari cela antara kalian, dan janganlah kalian saling menyaingi, dan janganlah kalian saling dengki, dan janganlah kalian saling membenci dan jadilah hamba-hamba Allah swt yang bersudara. Dan janganlah seseorang dari kalian melamar wanita yang telah dilamar oleh saudaranya sehingga ia menikahinya atau meninggalkannya" 18

6. Jurnalis Islami sebaiknya tidak menerima suap dalam menjalankan pekerjaannya, (QS al-Baqarah:188)

\footnotetext{
•・・口每 \&

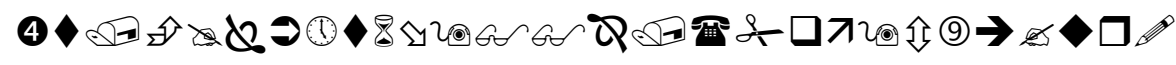

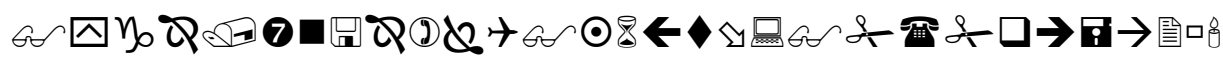

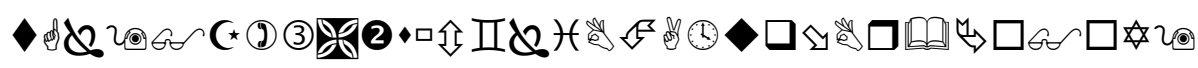

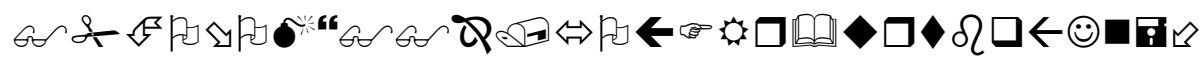

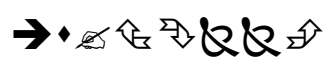


Terjemahnya:

"Dan janganlah sebahagian kamu memakan harta sebahagian yang lain di antara kamu dengan jalan yang bathil dan (janganlah) kamu membawa (urusan) harta itu kepada hakim, supaya kamu dapat memakan sebahagian daripada harta benda orang lain itu dengan (jalan berbuat) dosa, padahal kamu Mengetahui"19

Selain poin-poin di atas masih, beberapa pedoman akhlak Qur'ani yang wajib diperhatikan bagi seorang muslim yang berprofesi sebagai wartawan atau praktisi media adalah sebagai berikut:

a) Dalam menyampaikan informasi, waratawan muslim hendaknya melandasi dengan iktikad atau niat yang tinggi untuk senantiasa melakukan pengecekan kepada pihak-pihak yang bersangkutan sehingga tidak akan merugikan siapapun.

b) Ketika menyampaikan karyanya, wartawan muslim hendaknya menggunakan bahasa yang baik dan benar dalam gaya bahasa yang santun dan bijaksana. Dengan demikian apa yang disampaikannya akan dapat dimengerti, dirasakan, dan menjadi hikmat bagi khalayak.

c) Dalam melaksanakan tugas jurnalistik, hendaknya wartawan yang Islami melaksanakannya secara profesional dalam ikatan kerja yang produktif, sehingga karyanya akan memiliki hasil yang optimal dan adil untuk semua pihak sehingga ia akan dipandang sebagai aset utama perusahaan media.

d) Dalam melaksanakan tugas-tugasnya, jurnalis Islami hendaknya menghindarkan sejauh mungkin prasangka maupun pemikiran negatif sebelum menemukan kenyataan objektif berdasarkan pertimbangan yang adil dan berimbang dan diputuskan oleh pihak yang berwenang. 
e) Dalam kehidupan sehari-hari, jurnalis Islami hendaknya senantiasa dilandasi etika Islam dan gemar melakukan aktivitas sosial yang bermanfaat bagi umat. Sudah seharusnya selalu memperkaya wawasan keislamannya untuk meningkatkan amal ibadah sehari-hari.

f) Dalam melaksanakan tugasnya, jurnalis Islami hendaknya menjunjung tinggi asas kejujuran, kedisplinan dan selalu menghindarkan diri dari hal-hal yang akan merusak profesionalisme dan nama baik perusahaannya. Komitmen yang tinggi seyogyanya diberikan pada profesionalisme dan bukan ikatan primordialisme sempit.

g) Dalam melaksanakan tugasnya, juranalis Islami hendaknya senantiasa mempererat persaudaraan sesama profesi berdasarkan prinsip ukhuwah Islamiyah tanpa harus meninggalkan asas kompetisi sehat yang menjadi tututan perusahaan media massa modern.

h) Dalam melaksanakan tugasnya, jurnalis Islami hendaknya menyadari betul bahwa akibat dari karyanya akan memiliki pengaruh yang luas terhadap khalayak. Karena itu, hendaknya semua kegiatan jurnalistiknya ditujukan untuk tujuan-tujuan yang konstruktif dalam rangka pendidikan dan penerangan umat.

i) Dalam melaksanakan tugasnya, jurnalis Islami hendaknya menyadari dengan penuh kesadaran memahami banwa profesinya merupakan amanat Allah, umat dan perusahaan media. Karena itu jurnalis Islami hendaknya selalau siap mempertanggungjawabkan pekerjaannya kepada Allah, umat dan perusahaannya.

j) Dalam melaksanakan tugasnya, jurnalis Islami hendaknya selalu berkata atau menulis dengan prinsip-prinsip berbahasa yang diajarkan Al-Quran, yaitu qaulan ma'rufan (pantas), qaulan 
kariman (mulia), qaulan masyura (mudah dicerna), qaulan balighan (efektif/mengena), dan qaulan layyinan (lemah lembut). ${ }^{20}$

\section{Konsekuensi Hukum hubungan Antara Media dengan Politik}

Hubungan antara media dengan politik dapat dilihat sebagai suatu hal yang sangat menarik, terutama ketergantungan antara sumber berita dengan pihak yang memberitakan, namun di sisi lain hubungan itu cukup rawan jika para pekerja media tidak berhati-hati menjalankan tugas kewartawanannya secara professional, sebab itu bisa menimbulkan delik hokum. Ada beberapa hokum yang dapat menyeret para pekerja media ke dalam delik hokum antara lain:

a. Arogansi profesi, terutama para pekerja media yang berusia muda

b. Tidak menjaga privasi orang lain

c. Memandang proesi wartawan sebagai profesi istimewa

d. Melakukan malpraktik jurnalistik

e. SDM yang tidak professional, untuk bisa membedakan mana yang seharusnya diberitakan dan tidak bisa diberitakan

f. Mengacaukan masyarakat

g. Menabrak rambu-rambu Undang-Undang Pers dan penyiaran serta etika jurnalistik $^{21}$

Berikut rambu-rambu hUkum yang dapat menjerat seorang wartawan penerbit atau stasiun penyiaran menurut Harkristuti Harkrisnowo (Unesco, 2002): $:^{22}$

\begin{tabular}{|l|l|l|}
\hline \multicolumn{1}{|c|}{ Jenis } & \multicolumn{1}{c|}{ Pasal } & \multicolumn{1}{c|}{ Sanksi Maksimal } \\
\hline Penghinaan & $310 \mathrm{dst}$ & 9 bulan \\
\hline Pengaduan fitnah & 137 & 4 tahun \\
\hline Penghinaan kepada & 134,136 bis, 142, 143 & 5 tahun \\
\hline
\end{tabular}




\begin{tabular}{|c|c|c|}
\hline $\begin{array}{l}\text { Kepala Negara atau } \\
\text { wakil Kepala Negara }\end{array}$ & & \\
\hline $\begin{array}{l}\text { Penghinaan terhadap } \\
\text { golongan tertentu }\end{array}$ & 156 & 5 tahun \\
\hline $\begin{array}{l}\text { Penghinaan terhadap } \\
\text { pemerintah }\end{array}$ & 154 & 5 tahun \\
\hline $\begin{array}{l}\text { Penghinaan terhadap } \\
\text { penguasa umu }\end{array}$ & 207 & 7 tahun \\
\hline $\begin{array}{l}\text { Penghinaan terhadap } \\
\text { agama tertentu }\end{array}$ & $156 \mathrm{a}$ & 1 tahun 6 bulan \\
\hline Penghasutan & & 5 tahun \\
\hline Penawaran kejahatan & 161 & 6 tahun \\
\hline $\begin{array}{l}\text { Pembocoran rahasia } \\
\text { Negara }\end{array}$ & 112 & 4 tahun \\
\hline Pembocoran rahasia & 32 & 7 tahun \\
\hline Pornografi & 282 & 9 bulan \\
\hline Penyiaran kabar bohong & Pasal XIV UU 1/1946 & 1 tahun 6 bulan \\
\hline
\end{tabular}

Sumber: Hafied Cangara, Komunikasi Politik dalam Harkristuti Harkrisnowo, Unesco (2002)

Untuk menjalankan tugas-tugas jurnalistik secara professional dan terhindar dari rambu-rambu delik aduan maka diperlukan Undang-Undang Pers dan Kode Etik untuk dijadikan pegangan bagi setiap wartawan.

\section{SIMPULAN}

Dari penjelasan di atas, dapat ditarik kesimpulan sebagai berikut: pertama, jurnalistik islami yaitu proses peliputan dan pelaporan peristiwa yang mengandung pesan dakwah berupa ajakan ke jalan Allah swt. Setiap berita, 
artikel opini, ataupun feature yang mengandung seruan secara langsung dan tidak langsung, tersurat ataupun tersurat, untuk beriman, berbuat baik (beramal saleh), dan bertakwa kepada Allah swt masuk dalam kategori jurnalistik islami.Kedua, Landasan etika jurnalis Islami: (a) Menyampaikan informasi dengan benar, juga tidak merekayasa atau memanipulasi fakta (QS. Al-Hajj: 30), (b) Bijaksana penuh nasihat yang baik, serta argumentasi yang jelas dan baik pula. (QS. An-Nahl: 125), (c) Meneliti fakta atau cek-ricek. Untuk mencapai ketepatan data dan fakta sebagai bahan baku berita yang akan ditulis, jurnalis muslim hendaknya mengecek dan meneliti kebenaran fakta di lapangan dengan informasi awal yang ia peroleh agar tidak terjadi ghibah dan fitnah.(QS.Al-Hujurat: 6), (d) Tidak mengolok-olok, mencaci-maki, atau melakukan tindakan penghinaan sehingga menumbuhkan kebencian (QS. AlHujarat: 11), (e) Menghindari prasangkaatau su'udzon. Dalam pengertian hukum, jurnalis hendaknya memegang teguh "asas prduga tak bersalah" seperti yang tertulis pada QS Al-hujurat: 12, (f) Jurnalis Islami sebaiknya tidak menerima suap dalam menjalankan pekerjaannya, (QS Al-baqarah:188).

\footnotetext{
${ }^{1}$ William L. Rivers dan Cleve Mathews, Ethic for The Media diterjemahkan oleh Arwah Setiawan dan Danan Priyatmokop, ( Jakarta: Gramedia, 1994), h. 60.

${ }^{2}$ Warner J. Severin dan James W. Tankard, Jr , Teori Komunikasi, Sejarah, Metode dan Terapan di Dalam Media Massa (Cet. 5; Jakarta: Kencana, 2009), h. 83.

${ }^{3}$ Asep Syamsul M Romli, Jurnalistik Dakwah: Visi dan Misi Dakwah Bil Qolam, (Bandung: Rosdakarya, 2003), h. 32.

${ }^{4}$ Asep Syamsul M Romli, Jurnalistik Dakwah: Visi dan Misi Dakwah Bil Qolam, (Bandung: Rosdakarya, 2003), h. 33.
} 
${ }^{5}$ Kementerian Agama RI, Al-qur'an dan Terjemahnya, (Solo: PT. Tiga Serangkai Pustaka Mandiri, 2016), h. 63.

${ }^{6}$ Quraish Shihab, Tafsir Al-Misbah: Pesan Kesan, dan Keserasian Al-qur'an, (Jakarta: Lentera Hati, 2002), h. 209.

${ }^{7}$ Quraish Shihab, Tafsir Al-Misbah: Pesan Kesan, dan Keserasian Al-qur'an, (Jakarta: Lentera Hati, 2002), h. 210.

8Romel, Dasar-Dasar Jurnalistik Dakwah, (Jakarta: Romeltea Media, 2009), h. 47.

${ }^{9}$ Romel, Dasar-Dasar Jurnalistik Dakwah, (Jakarta: Romeltea Media, 2009), h. 91.

10 Persatuan Wartawan Indonesia Sulawesi Selatan, Kode Etik Jurnalistik, (Makassar: PWI Sulsel, 2006), h. 1.

${ }^{11}$ Persatuan Wartawan Indonesia Sulawesi Selatan, Kode Etik Jurnalistik, (Makassar: PWI Sulsel, 2006), h. 2-4.

${ }^{12}$ Hafied Cangara, Komunikasi Politik: Konsep Teori dan Strategi, (Cet. 4; Jakarta: Rajawali Pers, 2014), h. 85-86.

${ }^{13}$ Kementerian Agama RI, Al-qur'an dan Terjemahnya, (Solo: PT. Tiga Serangkai Pustaka Mandiri, 2016), h. 335.

${ }^{14}$ Kementerian Agama RI, Al-qur'an dan Terjemahnya, (Solo: PT. Tiga Serangkai Pustaka Mandiri, 2016), h. 281.

${ }^{15}$ Kementerian Agama RI, Al-qur'an dan Terjemahnya, (Solo: PT. Tiga Serangkai Pustaka Mandiri, 2016), h. 516.

${ }^{16}$ Kementerian Agama RI, Al-qur'an dan Terjemahnya, (Solo: PT. Tiga Serangkai Pustaka Mandiri, 2016), h. 516.

${ }^{17}$ Kementerian Agama RI, Al-qur'an dan Terjemahnya, (Solo: PT. Tiga Serangkai Pustaka Mandiri, 2016), h. 517.

${ }^{18}$ Kementerian Agama RI, Al-qur'an dan Terjemahnya, (Solo: PT. Tiga Serangkai Pustaka Mandiri, 2016), h. 517.

${ }^{19}$ Kementerian Agama RI, Al-qur'an dan Terjemahnya, (Solo: PT. Tiga Serangkai Pustaka Mandiri, 2016), h. 517.

${ }^{20}$ Romli, Majalah Al-Islamiyah, (Yogyakarta: Nomor 31 Tahun XIV, 2007), h. 19.

${ }^{21}$ Hafied Cangara, Komunikasi Politik: Konsep Teori dan Strategi, (Cet. 4; Jakarta: Rajawali Pers, 2014), h. 118.

${ }^{22}$ Hafied Cangara, Komunikasi Politik: Konsep Teori dan Strategi, (Cet. 4; Jakarta: Rajawali Pers, 2014), h. 120. 


\section{DAFTAR PUSTAKA}

Rivers, William L. dan Cleve Mathews.Ethic for The Media diterjemahkan oleh Arwah Setiawan dan Danan Priyatmokop.Jakarta: Gramedia. 1994.

Severin, Warner J.dan James W. Tankard. Jr.Teori Komunikasi, Sejarah, Metode dan Terapan di Dalam Media Massa .Cet. 5. Jakarta: Kencana. 2009.

Romli,Asep Syamsul M.Jurnalistik Dakwah: Visi dan Misi Dakwah Bil Qolam. Bandung: Rosdakarya. 2003.

Kementerian Agama RI. Al-qur'an dan Terjemahnya. Solo: PT. Tiga Serangkai Pustaka Mandiri. 2016.

Shihab, Quraish. Tafsir Al-Misbah: Pesan Kesan, dan Keserasian Al-qur'an. Jakarta: Lentera Hati, 2002.

Romel.Dasar-Dasar Jurnalistik Dakwah.Jakarta: Romeltea Media, 2009.

Persatuan Wartawan Indonesia Sulawesi Selatan.Kode Etik Jurnalistik. Makassar: PWI Sulsel. 2006.

Cangara, Hafied. Komunikasi Politik: Konsep Teori dan Strategi. Cet. 4. Jakarta: Rajawali Pers.2014.

Romli.Majalah Al-Islamiyah. Yogyakarta: Nomor 31 Tahun XIV. 2007. 